\title{
The conundrum of postpartum thrombotic Microangiopathy: case report and considerations for management
}

\author{
Katharina Artinger ${ }^{1}$, Gerald Hackl${ }^{2}$, Gernot Schilcher ${ }^{2}$, Florian Eisner ${ }^{2}$, Marion J. Pollheimer ${ }^{3}$, Christoph Mache ${ }^{4}$, \\ Eva-Christine Weiss ${ }^{5}$, Kathrin Eller ${ }^{1}$ and Philipp Eller ${ }^{2^{*}}$ (ID
}

\begin{abstract}
Background: Microangiopathic hemolytic anemias and thrombocytopenias in pregnant or postpartum women constitute an interdisciplinary diagnostic and therapeutic challenge in the evaluation of thrombotic microangiopathies (TMA), where urgent care must be considered.

Case presentation: We here report the case of a 21-year-old Somali woman, who was delivered by emergency caesarean section at 35 weeks of gestational age with acute dyspnea, placental abruption and gross edema due to severe preeclampsia/HELLP syndrome. After delivery, she developed acute kidney failure and thrombotic microangiopathy as revealed by kidney biopsy. The lack of early response to plasma exchange prompted extensive laboratory workup. Ultimately, the patient completely recovered with negative fluid balance and control of severe hypertension.

Conclusions: This case report emphasizes the importance to differentiate between primary TMA syndromes and microangiopathic hemolytic anemias due to systemic disorders. Delayed recovery from preeclampsia/HELLP syndrome and malignant hypertension can clinically mimic primary TMA syndromes in the postpartum period.
\end{abstract}

Keywords: Thrombotic microangiopathy, Preeclampsia, HELLP syndrome, Plasma exchange, Eculizumab

\section{Background}

Microangiopathic hemolytic anemias and thrombocytopenias in pregnant or postpartum women constitute an interdisciplinary diagnostic and therapeutic challenge in the evaluation of thrombotic microangiopathies (TMA), where urgent care must be considered for immediate treatment particularly of preeclampsia/HELLP (PE/ HELLP) syndrome, thrombotic thrombocytopenic purpura (TTP), and complement-mediated thrombotic microangiopathy [1-3].

\section{Case presentation}

We here report the case of a 21-year-old Somali woman, who was delivered by emergency caesarean section at 35 weeks of gestational age with acute dyspnea, placental

\footnotetext{
* Correspondence: philipp.eller@medunigraz.at

${ }^{2}$ Department of Internal Medicine, Intensive Care Unit, Medical University

Graz, Auenbruggerplatz 15, A-8036 Graz, Austria

Full list of author information is available at the end of the article
}

abruption and gross edema due to severe PE/HELLP syndrome. This was her first pregnancy, which had been uneventful up to the 34th gestational week. Her soluble fms-like tyrosine kinase-1/placental growth factor ratio 2 days prior was 211.4 [4]. After surgery, the patient was immediately transferred to Intensive Care Unit because of lung edema. The laboratory analysis revealed anemia of $7.4 \mathrm{~g} / \mathrm{dL}$, thrombocytopenia of $50 \mathrm{G} / \mathrm{L}$, a negative coombs test, increased serum lactate dehydrogenase of $690 \mathrm{U} / \mathrm{L}$, increased bilirubin of $2.2 \mathrm{mg} / \mathrm{dL}$, elevated aspartate transaminase of $150 \mathrm{U} / \mathrm{L}$, elevated alanine transaminase of 140 , creatinine of $1.19 \mathrm{mg} / \mathrm{dL}$, and no detectable haptoglobin levels $(<0.09 \mathrm{~g} / \mathrm{L})$. The peripheral blood smear showed manifold schistocytes $(2.8 \%)$ and the activated prothrombin time was $38.2 \mathrm{~s}$ (Additional file 1: Table S1). The PLASMIC score was high indicating a high pretest probability for TTP (>90\%) [5]. The patient displayed elevated systolic blood pressure between 160 and $200 \mathrm{mmHg}$

(c) The Author(s). 2019 Open Access This article is distributed under the terms of the Creative Commons Attribution 4.0 International License (http://creativecommons.org/licenses/by/4.0/), which permits unrestricted use, distribution, and reproduction in any medium, provided you give appropriate credit to the original author(s) and the source, provide a link to the Creative Commons license, and indicate if changes were made. The Creative Commons Public Domain Dedication waiver (http://creativecommons.org/publicdomain/zero/1.0/) applies to the data made available in this article, unless otherwise stated. 
despite of intensive blood pressure lowering medication including urapidil, nifedipin, furosemide, and dihydralazine. As concern for the diagnosis TTP was strong, we immediately initiated plasma exchange therapy (PEX) and glucocorticoid medication, and proceeded with further diagnostic evaluation over the next days (Fig. 1). While undergoing PEX, the renal retention parameters slowly increased over the next 4 days, reaching a serum creatinine level of $2.09 \mathrm{mg} / \mathrm{dL}$ and an estimated glomerular filtration rate of $33 \mathrm{~mL} / \mathrm{min} / 1.73 \mathrm{~m}^{2}$. In parallel, fibrinogen levels decreased to a nadir of $103 \mathrm{mg} / \mathrm{dL}$, and the thrombocyte count was still as low as $35 \mathrm{G} / \mathrm{L}$ on the 4th postoperative day. This decrease was associated with a peak of D-dimer level $(26.27 \mathrm{mg} / \mathrm{L})$ on the 6 th postoperative day. The lack of early response to PEX prompted us to discuss the need for anti-complement therapy with eculizumab and to seek for other causes of the patient's symptoms. There was no retained placental rest after delivery. In the meantime, ADAMTS13 activity had been measured and was found to be only slightly decreased to $39-63 \%$, thus excluding the diagnosis of TTP [6]. Shiga-toxin, malaria parasites, and HIV antigen/antibodies were not detectable, and the hepatitis $B$ and $C$ serology tests were negative. The screening test for antibodies to extractable nuclear antigens (ENA), antinuclear, antiphospholipid and anticardiolipin antibodies, as well as serum C3c $(0.917 \mathrm{~g} / \mathrm{L})$ and serum C4 levels $(0.113 \mathrm{~g} / \mathrm{L})$ were within normal ranges. Urinary analyses revealed an albuminuria of $4.2 \mathrm{~g} / \mathrm{g}$ and $40 \%$ acanthocytes, respectively. Since the patient presented with

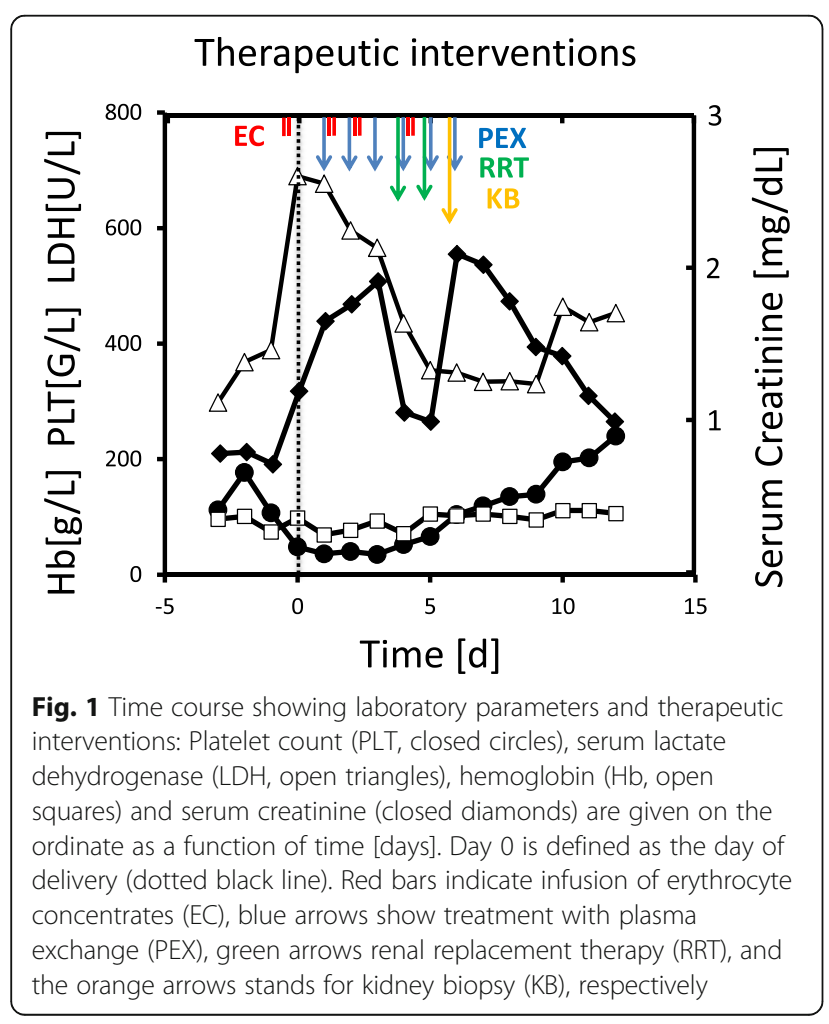

anasarca, somnolence, partial respiratory insufficiency due to lung edema and pleural effusions as well as still poorly controlled hypertension, we initiated a continuous renal replacement therapy with ultrafiltration on the 4th postoperative day, reducing the body weight of the patient from $70 \mathrm{~kg}$ to $49.5 \mathrm{~kg}$ in four days. Furthermore, PEX was daily continued. Along with the negative fluid balance of $20.5 \mathrm{~L}$, the patient drastically improved both clinically and with the laboratory parameters. In parallel, kidney biopsy was performed on the 6th postoperative day, which revealed a residual thrombotic microangiopathy and signs of malignant hypertension such as doubling of the basal membrane as well as mild tubular necrosis. Immune complex nephritis, e.g. lupus nephritis, was excluded (Fig. 2). Therefore, we stopped PEX on the 6th day postpartum, after having reached a thrombocyte threshold of $>100 \mathrm{G} / \mathrm{L}$. Dose and number of antihypertensive medication were drastically decreased. In a serum sample drawn prior to PEX, we found no evidence of complement activation

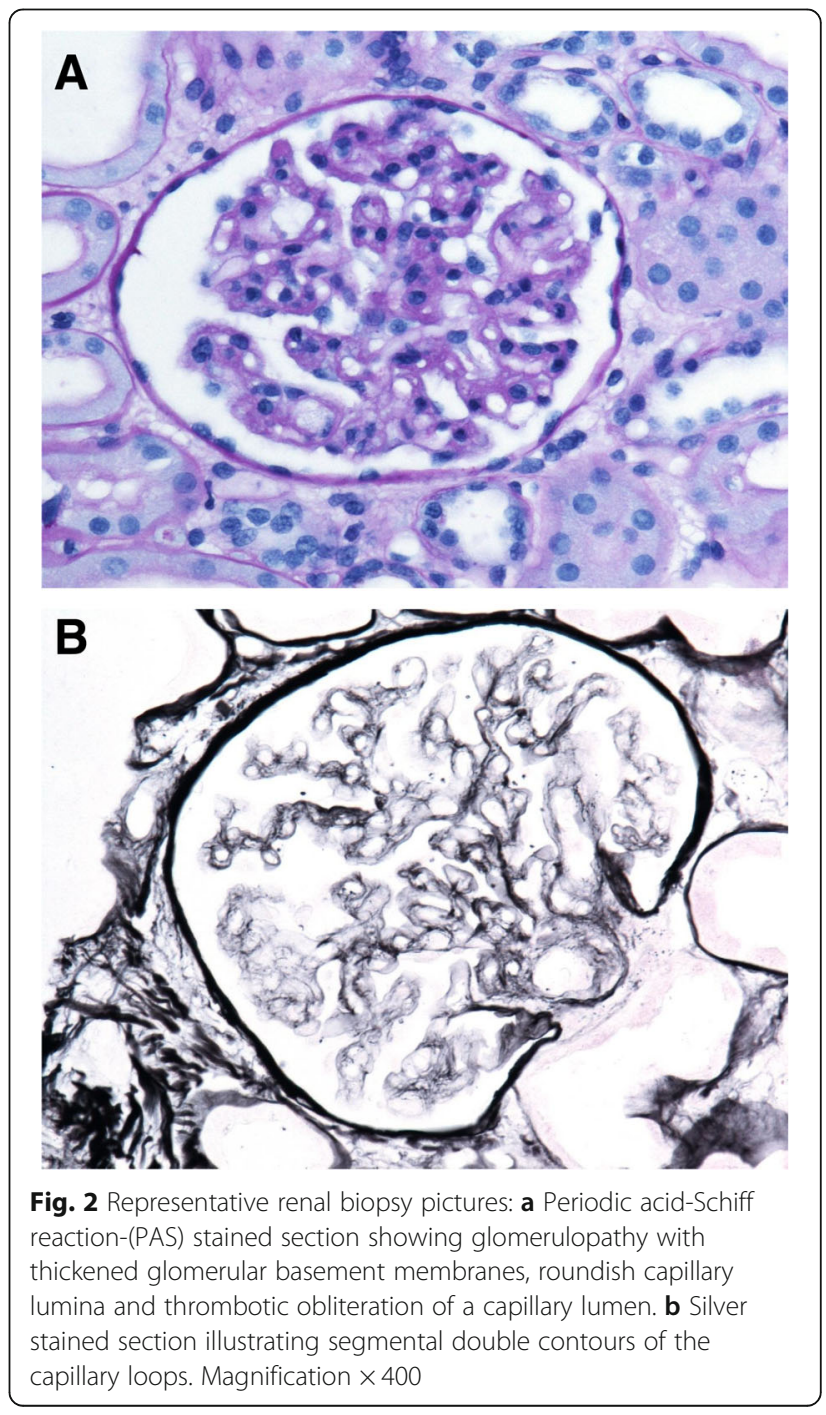


using an in-vitro assay for complement deposition on non-activated endothelial cells (Fig. 3). C3c and C5b-9 complement deposition assays were performed as described previously by Noris et al. [7] Moreover, there were neither anti-complement factor $\mathrm{H}$ antibodies as determined by ELISA, nor mutations of atypical hemolytic uremic syndrome-related genes $A D A M T S 13, C 3, C F B$, CFB, CFH, CFHR1, CFHR2, CFHR3, CFHR4, CFHR5, CFI, $D G K E, M C P / C D 46, M M A C H C$, and THBD as detected by next-generation sequencing [8]. The patient completely recovered without further need for renal replacement therapy and/or PEX. Thrombocyte count increased to $240 \mathrm{G} / \mathrm{L}$, and creatinine serum levels decreased to 0.99 $\mathrm{mg} / \mathrm{dL}$ on the 12 th day after delivery. The patient was discharged from Intensive Care Unit after 10 days, and dismissed from Hospital on the 16th day postpartum without any chronic impairment of glomerular filtration rate. Twenty-eight days after delivery, the glomerular filtration rate was $127.7 \mathrm{~mL} / \mathrm{min} / 1.73 \mathrm{~m}^{2}$, and serum creatinine was $0.64 \mathrm{mg} / \mathrm{dL}$. Moreover, urinary albumin/creatinine ratio recovered from $4.2 \mathrm{~g} / \mathrm{g}$ to $0.55 \mathrm{~g} / \mathrm{g}$ within 4 weeks.

The patient had given birth to a daughter who had an Apgar score of 8/9/10, a body weight of $2260 \mathrm{~g}$ (26th
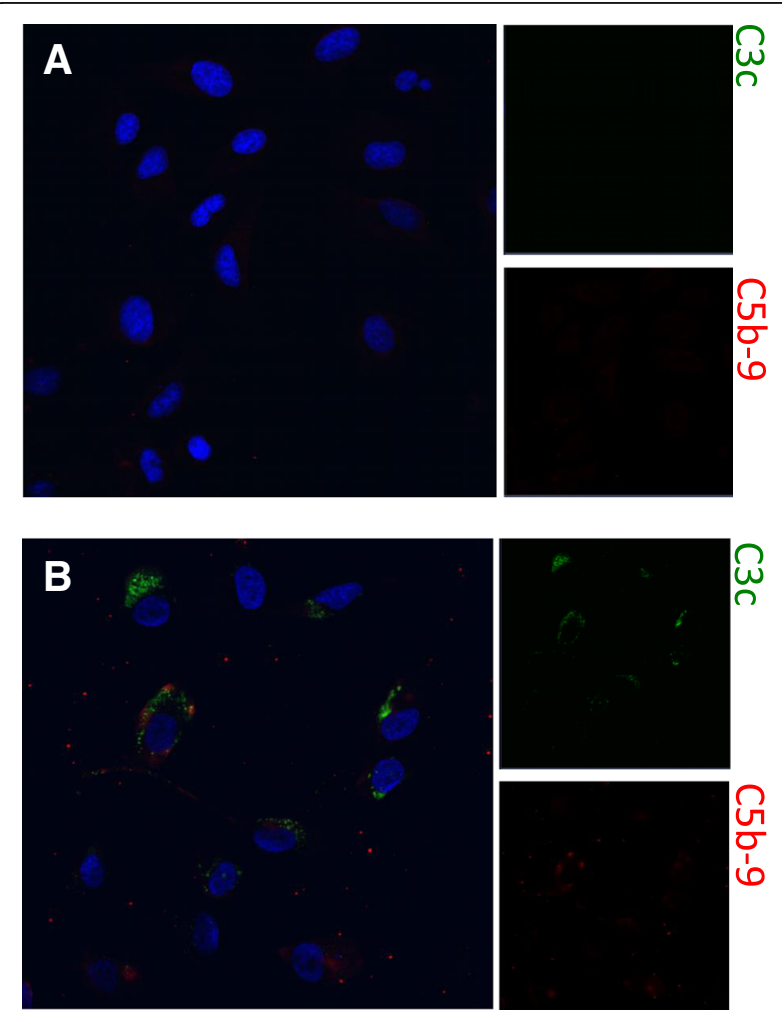

Fig. 3 Complement deposition on endothelial cells: Endothelial cells were incubated with $\mathbf{a}$ serum from the index patient and $\mathbf{b}$ control serum from a patient with acute complement-mediated TMA due to complement factor $\mathrm{H}$ mutation. Serum of the index patient caused no deposition of C3c (FITC) and C5b-9 (Rhodamine) on non-activated endothelial cells. Magnification $\times 40$ percentile), and a length of $46 \mathrm{~cm}$. The daughter did not have increased perinatal morbidity.

\section{Methods for cell culture and complement deposition assay}

Ea.hy 926 cells (human endothelial cell line) were cultured in DMEM low Glucose medium (Gibco, Thermo Fisher Scientific, Waltham, MA, USA) containing 10\% fetal bovine serum, Antibiotic-Antimycotic (Gibco, Thermo Fisher Scientific), and HAT Supplement (Gibco, Thermo Fisher Scientific) on cell chamber slides and used when confluent. C3c and C5b-9 complement deposition assays were performed as described previously. Briefly, cells were incubated with patient serum (1:2 dilution) or control serum for 4 hours. Cells were then stained with FITC-conjugated polyclonal rabbit anti-human C3c complement antibody (F0201, DAKO, Glosturp, Denmark) and monoclonal mouse anti-human C5b-9 antibody (ab66768, Abcam, Cambridge, MA, USA), followed by secondary antibody incubation with Rhodamine (TRITC)-conjugated goat anti-mouse (115025-146, Jackson Immuno Research Laboratories, West Grove, PA, USA). Rb IgG Isotype Control FITC (PA523092, Thermo Scientific) and Mouse IgG2a Isotype Control (MCA929, Bio-Rad, Hercules, CA, USA) were used as appropriate isotype control antibodies. Stained cells were mounted with ProLong Gold Antifade Mountant with DAPI (Thermo Scientific). Evaluation of C3 and C5b-9 complement deposition on human endothelial cells was performed on a LSM 510 confocal microscope (Zeiss, Oberkochen, Germany).

\section{Discussion and conclusions}

Taken together, this case report emphasizes the importance to differentiate between primary TMA syndromes and microangiopathic hemolytic anemias due to systemic disorders [3-5]. Delayed recovery from PE/HELLP syndrome and severe hypertension can clinically mimic primary TMA syndromes in the postpartum period. Since the diagnostic approach is costly in terms of time, it is nevertheless important to start standard therapy including PEX and revisit the first tentative diagnosis with the incoming diagnostic results as well as the clinical course of disease.

\section{Additional file}

Additional file 1: Table S1. Normal ranges of laboratory parameters. (DOCX 16 kb)

Abbreviations

PE/HELLP: Preeclampsia/HELLP syndrome; PEX: Plasma exchange therapy;

TMA: Thrombotic microangiopathy; TTP: Thrombotic thrombocytopenic purpura 


\section{Acknowledgements}

Not applicable.

\section{Funding}

K. Artinger was enrolled in the PhD program in Molecular Medicine at the Medical University of Graz. P. Eller and K. Eller received grant support by the Austrian Science Funds (FWF) (P27537-B26). The funding body did not have any role in the design of the study, and collection, analysis and interpretation of data and in writing the manuscript.

\section{Availability of data and materials}

The datasets used and/or analysed during the current study are available from the corresponding author on reasonable request.

\section{Authors' contributions}

ECW performed the Caesarean section, KE performed the kidney biopsy, MJP performed the histopathological stainings, KA performed cell culture and complement deposition assay, CM performed the genetic analyses for mutations of atypical hemolytic uremic syndrome-related genes. GS, GH, FE, and PE treated the patient on ICU. PE and KE analysed the data and wrote the manuscript. ECW, MJP, KA, CM, GS, GH and FE critically revised the manuscript for important intellectual content. All authors approved the fina version of the manuscript and agreed to be accountable for all aspects related to accuracy and integrity of the work.

\section{Ethics approval and consent to participate}

The Institutional Review Board of the Medical University of Graz approved this clinical study (EK-Nr.: 29-471 ex 16/17).

\section{Consent for publication}

Written informed consent was obtained from the patient for publication of this case report.

\section{Competing interests}

The authors declare that they have no competing interests.

\section{Publisher's Note}

Springer Nature remains neutral with regard to jurisdictional claims in published maps and institutional affiliations.

\section{Author details}

'Department of Internal Medicine, Clinical Division of Nephrology, Medical University of Graz, Graz, Austria. ${ }^{2}$ Department of Internal Medicine, Intensive Care Unit, Medical University Graz, Auenbruggerplatz 15, A-8036 Graz, Austria. ${ }^{3}$ Institute of Pathology, Medical University of Graz, Graz, Austria. ${ }^{4}$ Department of Pediatrics and Adolescent Medicine, Division of General Pediatrics, Medical University of Graz, Graz, Austria. ${ }^{5}$ Department of Obstetrics and Gynecology, Medical University of Graz, Graz, Austria.

Received: 10 October 2017 Accepted: 7 March 2019

Published online: 14 March 2019

\section{References}

1. George JN, Nester CM, Mclntosh JJ. Syndromes of thrombotic microangiopathy associated with pregnancy. Hematology Am Soc Hematol Educ Program. 2015. https://doi.org/10.1182/asheducation-2015.1.644.

2. George JN, Nester CM. Syndromes of thrombotic microangiopathy. N Engl J Med. 2014. https://doi.org/10.1056/NEJMra1312353.

3. Bruel A, Kavanagh D, Noris M, Delmas Y, Wong EKS, Bresin E, et al Hemolytic uremic syndrome in pregnancy and post-partum. Clin J Am Soc Nephrol. 2017. https://doi.org/10.2215/CJN.00280117.

4. Zeisler H, Llurba E, Chantraine F, Vatish M, Staff AC, Sennström M, et al. Predictive value of the sFlt-1:PIGF ratio in women with suspected preeclampsia. N Engl J Med. 2016. https://doi.org/10.1056/NEJMoa1414838

5. Bendapudi PK, Hurwitz S, Fry A, Marques MB, Waldo SW, Li A, et al. Derivation and external validation of the PLASMIC score for rapid assessment of adults with thrombotic microangiopathies: a cohort study. Lancet Haematol. 2017. https://doi.org/10.1016/S2352-3026(17)30026-1.

6. Cines DB, Levine LD. Thrombocytopenia in pregnancy. Blood. 2017 https://doi.org/10.1182/blood-2017-05-781971.
7. Noris M, Galbusera M, Gastoldi S, Macor P, Banterla F, Bresin E, et al. Dynamics of complement activation in aHUS and how to monitor eculizumab therapy. Blood. 2014. https://doi.org/10.1182/blood-2014-02-558296.

8. Fremeaux-Bacchi V, Fakhouri F, Garnier A, Bienaimé F, Dragon-Durey MA, Ngo S, et al. Genetics and outcome of atypical hemolytic uremic syndrome: a nationwide French series comparing children and adults. Clin J Am Soc Nephrol. 2013. https://doi.org/10.2215/CJN.04760512.

\section{Ready to submit your research? Choose BMC and benefit from:}

- fast, convenient online submission

- thorough peer review by experienced researchers in your field

- rapid publication on acceptance

- support for research data, including large and complex data types

- gold Open Access which fosters wider collaboration and increased citations

- maximum visibility for your research: over $100 \mathrm{M}$ website views per year

At BMC, research is always in progress.

Learn more biomedcentral.com/submissions 